\title{
Acid-basic surface properties of clay disperse fillers
}

\author{
Yuliya Danchenko ${ }^{1, *}$, Vladimir Andronov ${ }^{2}$, Viktor Sopov ${ }^{1}$, Igor $\mathrm{Khmyrov}^{2}$, and Anton \\ Khryapynskyy $^{2}$ \\ ${ }^{1}$ Kharkiv National University of Civil Engineering and Architecture, Sumska str., 40, 61002, Kharkiv, \\ Ukraine \\ ${ }^{2}$ National University of Civil Protection of Ukraine, Chernyshevska str., 94, 61023, Kharkiv, Ukraine
}

\begin{abstract}
The mineral composition, surface morphology, dispersion and specific surface of dispersed clay fillers of various chemical nature have been experimentally determined. As materials for research used clay mineral disperse fillers of various chemical and mineral composition: bentonite clay, kaolinite clay and diabase flour. Using the thermogravimetric (TG) analysis and the differential thermal analysis (DTA), the structure of the hydroxyl-hydrated surface layer of the filler surface has been studied. The amount and acidity of the surface active centers of clay fillers have been investigated using pK-metric and $\mathrm{pH}-$ metric methods. It was established that the mineral composition is the determining factor in the acid-base surface properties of clay fillers. The thickness of the hydroxyl-hydrated surface layer affects the acidity of the surface, at certain large sizes. It has been shown that clay fillers, which include montmorillonite as the dominant minerals, are characterized by higher acidity than the fillers that consist of kaolinite. In the mixed clay fillers, the acid-base properties of the surface depend on the chemical nature of the impurities and related minerals.
\end{abstract}

\section{Introduction}

Natural clay disperse fillers are widely used in the development of new polymer composites and other composite materials of various applications. Cheap clay fillers are added to composites in order to increase the economic and environmental attractiveness of building and restoration polymer materials. Addition of clay fillers allows adjusting the technological properties of compositions and improving the physical, mechanical and performance characteristics of materials [1-7]. Disperse clay fillers of various chemical and mineral nature can provide special properties to materials (for example, resistance to biologically aggressive media, fire resistance, vibration absorbing properties, etc.) [2-4]. In this case, the materials become multifunctional, that is, they can simultaneously provide several necessary operational or technological requirements. Moreover, adding clay fillers ensures the production of polymer materials with certain decorative properties, which is important when used in architecture, restoration and design [8,9]. Materials of different

* Corresponding author: $\underline{\mathrm{u} \_ \text {danchenko@ukr.net }}$ 
colours, either matte or glossy, may be produced, with imitation of the appearance of natural materials, etc.

\section{Literature review}

Investigation of the patterns of the influence of disperse clay fillers on the properties of dispersed filled materials solves the problem of obtaining new multifunctional composites with adjustable characteristics for construction, architecture, restoration, transport and other industries. Interest in this area is primarily due to the study of the physic-chemistry of surface phenomena in composite materials. The urgency of this direction arises in the process of creating new polymer composites, which are heterogeneous systems with highly developed phase separation surfaces. Properties of the surface of the dispersed phase determine the initial stage of adhesion interaction between the components - adsorption, wetting, spreading of the polymer on the surface of the filler, forming the boundary of phase separation, impregnation of filled and reinforced systems. Of all the existing theories of phase interaction in polymer composite materials, the least studied acid-base, the existence of which is confirmed by studies of recent years [10,11]. When choosing components of composite material, it is important to predict interactions on the interphase surface, which are simultaneously determined by the acid-base properties of the polymer and the acid strength of adsorption centers on the surface of the fillers.

Due to the natural origin of clay fillers, the chemical and mineralogical composition, and, consequently, the surface properties, are extremely unstable. In this case, the particles have superfluous surface energy and easily adsorb molecules of water from the air $[12,13]$. The effect of chemically and physically adsorbed water on the acid-base properties of the surface of inorganic materials is confirmed experimentally. It has been proved that the number and acid-base parameters of surface active centers change during burning or machining (milling) [6]. At adsorption of water on the surface formed hydroxyl-hydrated layer, which is characterized by a wide spectrum of active adsorption centers, the acid-basic properties of which are of great scientific interest [14], but not sufficiently studied.

The structure of the adsorption surface layer consists of chemically bound water molecules that form the first hydroxyl layer of OH-groups (Brensted's centers) and the following hydrated layers from water molecules bound to a hydroxyl layer due to hydrogen bonds. On the surface, the aprotonic acid and the base centers of Lewis, which are apparently small on air-dry surfaces, may be present. The determination of the acid-base characteristics of the active centers of the surface layer of inorganic materials is a complex but very important task. For this purpose, methods are used to determine the quantity and acid-base parameters of surface active centers, mainly experimentally [15, 16]. For example, the methods of IR spectroscopy, adsorption of gases in a gaseous medium or color indicators in liquids, by the method of potentiometric titration of suspensions. Experimental methods are informative but time-consuming and do not allow to determine the chemical nature of active centers. For the determination of the chemical nature of the active centers and the investigation of the protolytic equilibrium on the surface of inorganic materials, a method of quantum-chemical modeling is proposed [14].

Taking into account the fact that the surface properties of clay materials are directly related to the chemical and mineral composition, it is necessary to study the correlation between them. Thus, the task of this work involves installing the above-mentioned relationships. This will create opportunities for predicting the surface acid-base properties of clay disperse fillers, and also help to optimize the processes of developing new dispersed polymer composite materials with certain technological and operational characteristics. 


\section{Materials and methods of the study}

As materials for research, clay disperses fillers of various chemical and mineral compositions: bentonite clay (BC), kaolinite clay (KC) and diabase flour (DF) have been selected. For selected materials, experimental studies were carried out on the establishment of mineral composition, dispersion, surface morphology and surface area of particles. The surface area of the fillers was determined by the method of BET (Brunauer, Emmett, Teller). X-ray diffraction analysis was carried out on a X-ray diffractometer DRON-2 (Russia). Surface morphology and dispersion studies were performed using scanning electron microscope of the JSM-6390LV mark (Japan). Thermogravimetric (TG) analysis and Differential Scanning Calorimetry / Differential Thermal Analysis (DTA) with the use of the thermal analyzer of the brand SDT Q600 manufactured by TA Indstruments (USA) were performed for the investigation of the hydroxyl-hydrated surface layer of fillers.

Two methods were used to characterize the surface acid-base properties of clay fillers.

1) pKa-metric experimental method for determining the number of surface active centers by adsorption of Gamet color indicators from aqueous solutions and photocolorimetric measurements of optical density. As a result, the calculated total acid centers $\Sigma q_{A}$ with $p K_{a}<$ 7, the base centers $\Sigma q_{B}$ with $p K_{B}>7$, the total number of surface centers $\Sigma q=\Sigma q_{A}+\Sigma q_{B}$ and the acid-basic index $Q=\Sigma q_{A} / \Sigma q_{B}$. The obtained index makes it possible to estimate the surface as a whole as a neutral $(Q \approx 1)$, acidic $(Q>1)$ or basic $(Q<1)$. It is assumed that the higher the value of $Q$, the more acidic properties are characterized by the surface. The integral surface acidity index $Q$ has some advantages and disadvantages. The main disadvantage is that the value of $Q$ does not allow estimating the acid-base properties of the surface by Lewis, and this requires additional experimental studies (for example, the method of adsorption of gas molecules). Advantages are the possibility of a more complete understanding of the acid-base nature of the surface of any disperse materials or fillers within a small number of experimental and settlement operations [5, 7].

2) $\mathrm{pH}$-metric experimental method with potentiometric measurements of $p H^{\text {eq }}$ susp of aqueous suspensions of fillers in the process of establishing equilibrium state. Taking into account the $p H_{0}$ of pure water, the values $p H_{I I P}$ (isoadsorption point) of aqueous suspensions in the equilibrium state were calculated, which correspond to the arithmetic mean of $p K_{a}$ of the surface active centers of fillers:

$$
\begin{gathered}
p H_{I I P}=1 / n \cdot \sum_{i=1}^{n}\left(p K_{a 1}+p K_{a 2}+\ldots+p K_{a i}\right), \\
p H_{I I P}=p H_{0}+\left(p H_{\text {susp }}^{\text {eq }}-p H_{0}\right) \cdot\left(p H_{0}-6\right) .
\end{gathered}
$$

For the approximate estimation of the spectrum of active surface centers of fillers, the value of $\Delta p H=p H_{I I P}-p H^{e q}$ susp, which indicates the width of the range of $p K_{a}$ centers on the surface, was calculated. An increase in the value of $\Delta p H$ shows the expansion of the spectrum of active centers on the surface of the fillers. According to the potentiometric studies, the duration of the establishment of the equilibrium state in the suspension was established for an approximate quantitative assessment of the active surface centers. The duration of the establishment of the equilibrium state in the suspension can characterize the total number of acid-base surface active centers that take part in interactions with water molecules.

\section{Discussion of the results of the study}

The results of the study of mineral composition, dispersion and surface area of clay fillers are presented in Table 1 and in Fig. 1-3. 
Table 1. Properties of clay disperse fillers.

\begin{tabular}{|c|c|c|c|}
\hline Filler & $\begin{array}{l}\text { Mineralogical } \\
\text { composition }\end{array}$ & $\begin{array}{c}\text { Surface } \\
\text { area, } \mathrm{m}^{2} / \mathrm{g}\end{array}$ & $\begin{array}{l}\text { Average particle } \\
\text { size } d, \mu \mathrm{m}\end{array}$ \\
\hline $\begin{array}{l}\text { Bentonite clay } \\
\text { (BC) }\end{array}$ & $\begin{array}{c}\text { Montmorillonite } \\
(\mathrm{Al}, \mathrm{Mg})_{2}(\mathrm{OH})_{2}\left[\mathrm{Si}_{4} \mathrm{O}_{10}\right] \mathrm{nH}_{2} \mathrm{O} \\
\beta \text {-quartz } \mathrm{SiO}_{2}^{+} \\
\text {Kaolinite } \mathrm{Al}_{2} \mathrm{Si}_{2} \mathrm{O}_{5}(\mathrm{OH})_{4}{ }^{+}\end{array}$ & 15.62 & $10-20$ \\
\hline $\begin{array}{l}\text { Diabase flour } \\
\text { (DF) }\end{array}$ & $\begin{array}{c}\beta \text {-quartz } \mathrm{SiO}_{2}{ }^{\bullet} \\
\text { Montmorillonite } \\
(\mathrm{Al}, \mathrm{Mg})_{2}(\mathrm{OH})_{2}\left[\mathrm{Si}_{4} \mathrm{O}_{10}\right] \mathrm{nH}_{2} \mathrm{O}^{\bullet} \\
\text { Orthoclase } \mathrm{K}_{2} \mathrm{O}^{\circ} \mathrm{Al}_{2} \mathrm{O}_{3} \cdot 6 \mathrm{SiO}_{2} \\
\text { Leucite } \mathrm{K}_{2} \mathrm{O}^{\cdot} \mathrm{Al}_{2} \mathrm{O}_{3} \cdot 4 \mathrm{SiO}_{2} \\
\text { Lymonit } \mathrm{Fe}_{2} \mathrm{O}_{3} \cdot \mathrm{H}_{2} \mathrm{O}^{+}\end{array}$ & 1.90 & $2-4$ \\
\hline $\begin{array}{l}\text { Kaoline clay } \\
\text { (KC) }\end{array}$ & $\begin{array}{c}\text { Kaolinite } \mathrm{Al}_{2} \mathrm{Si}_{2} \mathrm{O}_{5}(\mathrm{OH})_{4}{ }^{\bullet} \\
\beta \text {-quartz } \mathrm{SiO}_{2}{ }^{+} \\
\text {Biotite } \\
(\mathrm{Fe}, \mathrm{Mg})_{3}[\mathrm{OH}]_{2}(\mathrm{Al}, \mathrm{Fe}) \mathrm{Si}_{3} \mathrm{O}_{10}{ }^{+} \\
\text {Hydrous micas } \\
(\mathrm{K}, \mathrm{Na}) \mathrm{Al}_{2}(\mathrm{Si}, \mathrm{Al})_{4} \mathrm{O}_{10}(\mathrm{OH})_{2} \mathrm{nH}_{2} \mathrm{O}^{+}\end{array}$ & 8.78 & $4-5$ \\
\hline
\end{tabular}

Remarks: $\bullet$ - basic mineral phase; + - side mineral phase; * - traces.
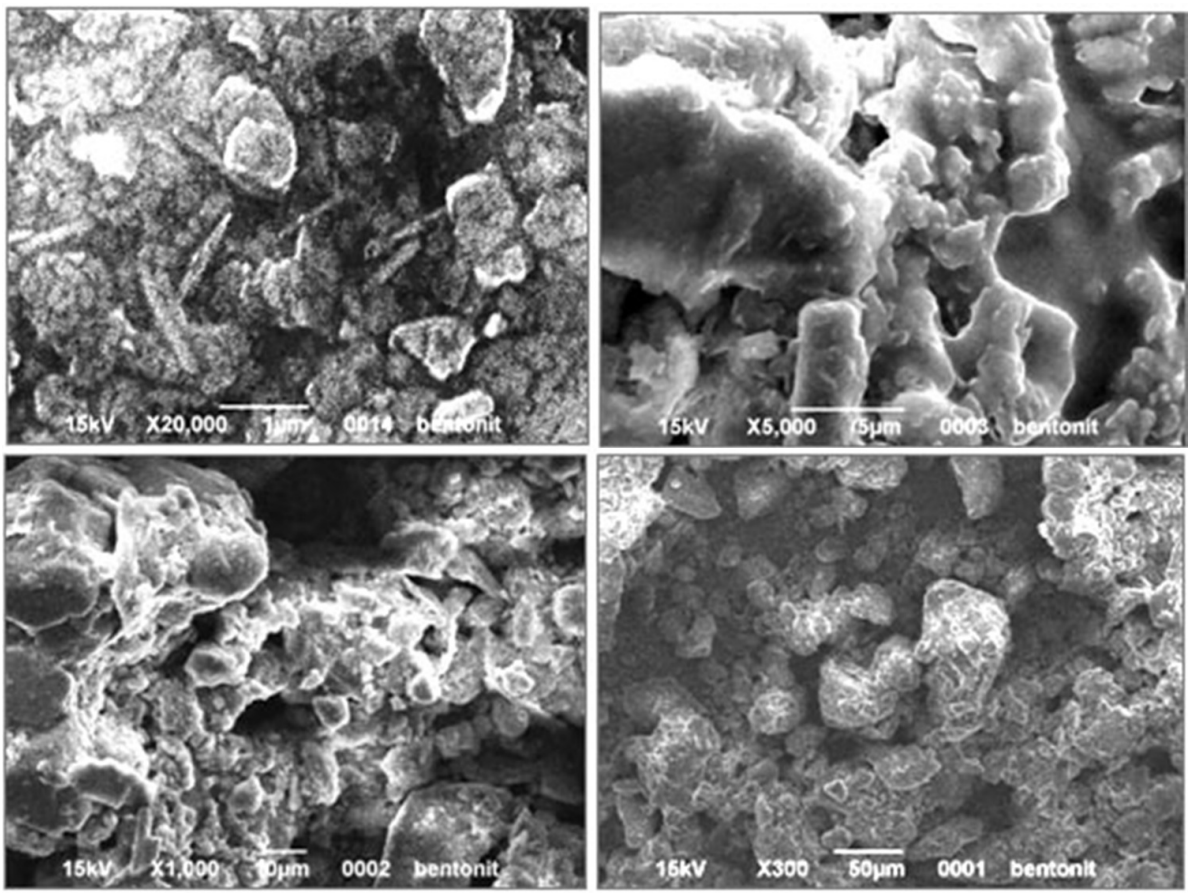

Fig. 1. Microphotographs for bentonite clay. 

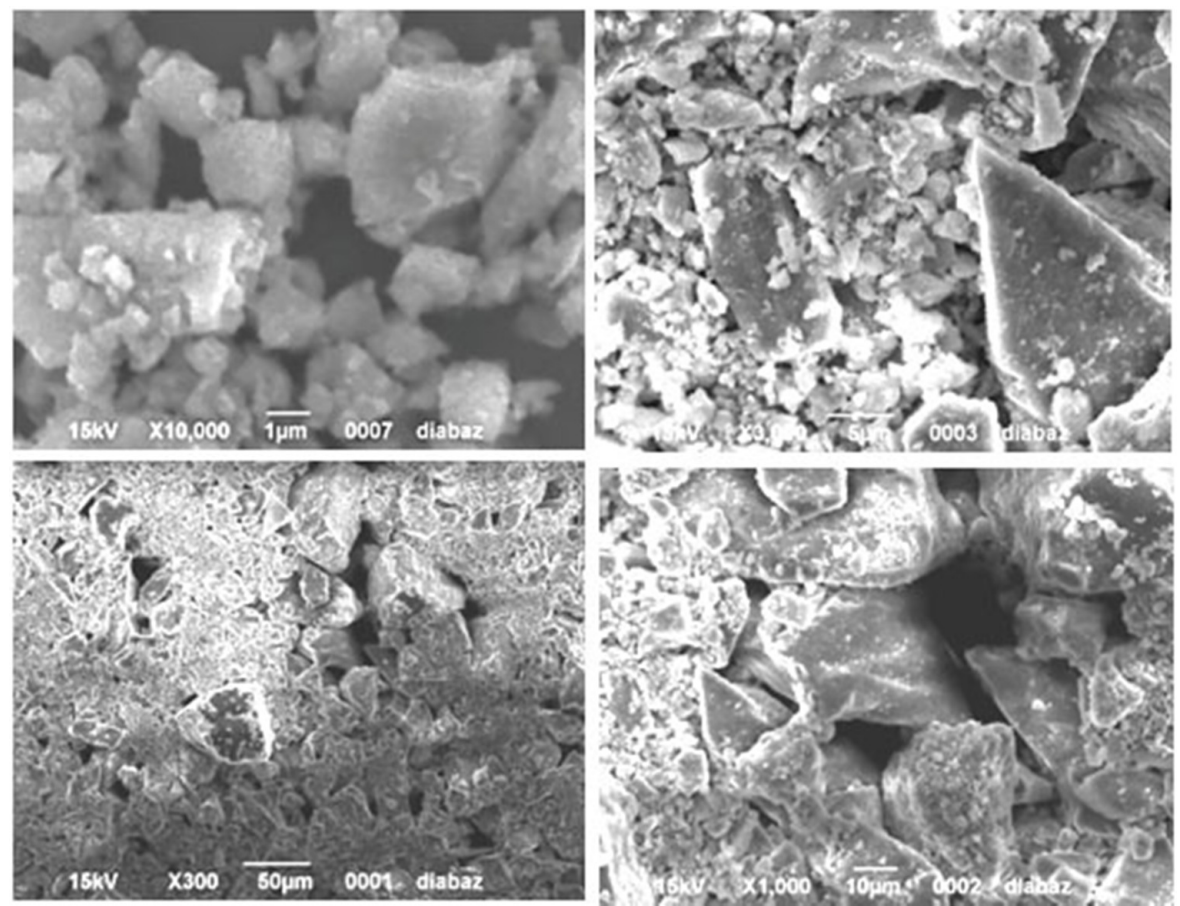

Fig. 2. Microphotographs for diabase flour.
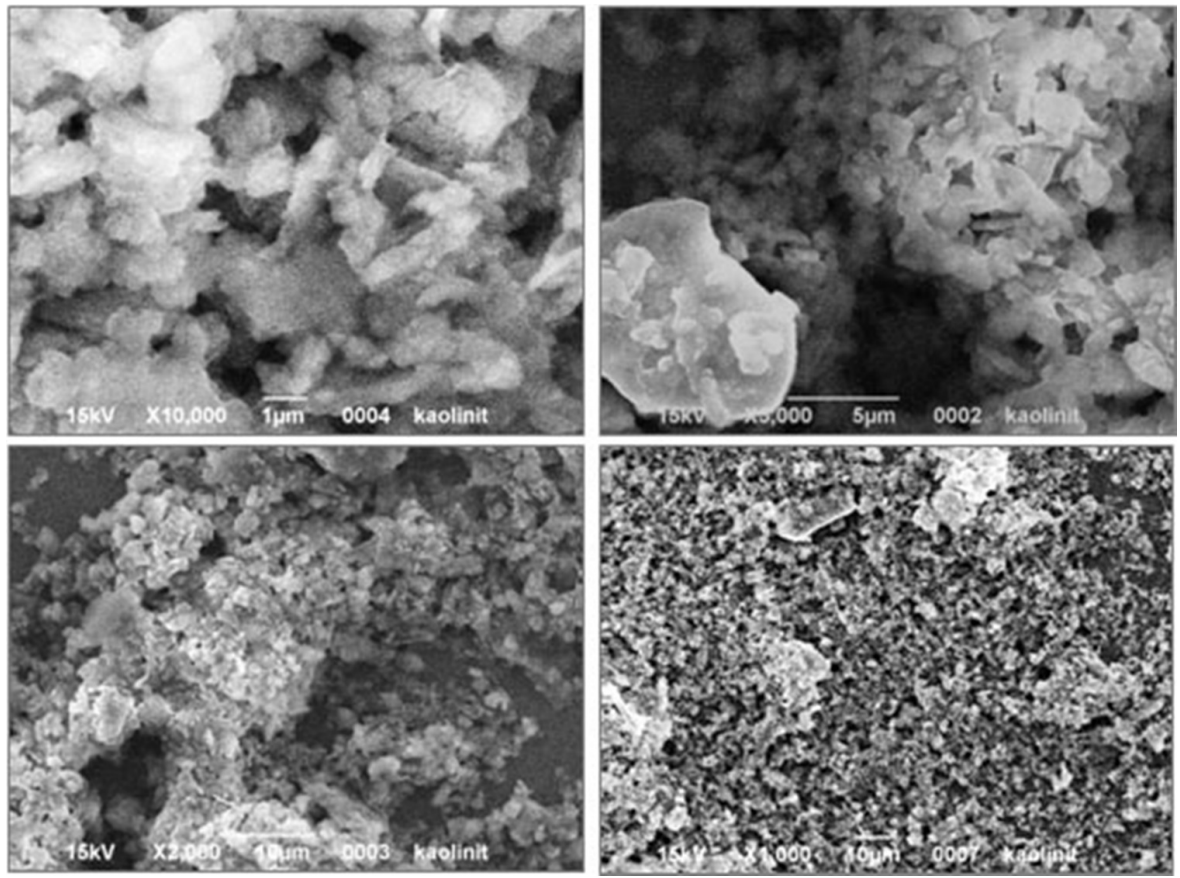

Fig. 3. Microphotographs for kaolinite clay.

Microphotographs of bentonite clay are presented in Fig. 1. The roentgenogram of bentonite clay is represented by a set of diffuse diffraction maxima of weak intensity corresponding to minerals of the montmorillonite group (montmorillonite and beidelite). 
Accompanying are kaolinite and $\beta$-quartz. Microphotographs show scaly grains of clay minerals and individual rhomboidric grains of quartz with a size of 1-1.5 $\mu \mathrm{m}$. Fine grains of clay minerals smaller than $0.5 \mu \mathrm{m}$ are assembled in aggregates of $10-20 \mu \mathrm{m}$, and some large $(50-60 \mu \mathrm{m})$ particles occur. Microphotographs of diabase flour are presented in Fig. 2. Diabase flour is a product of fine grinding in ball mills of acid-resistant magmatic rocks (diabase). Diabase flour is an agglomerated powder containing the leucite $\mathrm{K}_{2} \mathrm{O}^{\cdot} \cdot \mathrm{Al}_{2} \mathrm{O}_{3} \cdot 4 \mathrm{SiO}_{2}$, orthoclase $\mathrm{K}_{2} \mathrm{O}^{\cdot} \cdot \mathrm{Al}_{2} \mathrm{O}_{3} \cdot 6 \mathrm{SiO}_{2}, \mathrm{SiO}_{2}$ quartz, montmorillonite $(\mathrm{Al}, \mathrm{Mg})_{2}(\mathrm{OH})_{2}\left[\mathrm{Si}_{4} \mathrm{O}_{10}\right] \mathrm{nH}_{2} \mathrm{O}$ and lemonite $\mathrm{Fe}_{2} \mathrm{O}_{3} \cdot \mathrm{H}_{2} \mathrm{O}$ as the main phases) (Table 1). Isometric particles, collected in agglomerates with a size of 2-4 $\mu \mathrm{m}$. Large particles with a size of 40-50 $\mu \mathrm{m}$ have a shell fragmentation, covered with scaly formations, apparently montmorillonite and limonite. Microphotographs of kaolinite clay are presented in Fig. 3. Kaolinite clay is a dispersed mineral material of yellowish color. Hydrous micas, biotite $(\mathrm{Fe}, \mathrm{Mg})_{3}[\mathrm{OH}]_{2}(\mathrm{Al}, \mathrm{Fe}) \mathrm{Si}_{3} \mathrm{O}_{10}$ and $\beta$-quartz are present as accompanying minerals in powder composition (Table 1). The powder has a homogeneous disperse composition. Microphotographs show agglomerates of 4-5 $\mu \mathrm{m}$ in size, which are formed from scalable kaolinite crystals of hydrous micas crystals with a size of $0.5-1 \mu \mathrm{m}$. Less common are large dense isometric particles of quartz size 10$12 \mu \mathrm{m}$.

In Table 2 show the dynamics of mass loss of clay fillers in the process of increasing temperature.

Table 2. Loss of mass of clay disperse fillers in the process of temperature increase.

\begin{tabular}{|c|c|c|c|c|}
\hline \multirow{2}{*}{ Filler } & \multicolumn{4}{|c|}{ Weight loss of the filler in the temperature range, \% } \\
\cline { 2 - 5 } & $0-150^{\circ} \mathrm{C}$ & $150-300^{\circ} \mathrm{C}$ & $300-600^{\circ} \mathrm{C}$ & $600-900^{\circ} \mathrm{C}$ \\
\hline $\begin{array}{c}\text { Bentonite clay } \\
\text { (BC) }\end{array}$ & 0.7 & 0 & 8.8 & 0.5 \\
\hline $\begin{array}{c}\text { Diabase flour } \\
\text { (DF) }\end{array}$ & 1.0 & 0.8 & 1.1 & 0.4 \\
\hline $\begin{array}{c}\text { Kaoline clay } \\
\text { (KC) }\end{array}$ & 0.6 & 0.3 & 12.2 & 1.3 \\
\hline
\end{tabular}

From the results presented in Table 2 it is possible to draw the following conclusions. At temperatures of $0-300^{\circ} \mathrm{C}$, processes of dehydration, that is, the loss of physically adsorbed on the surface of water molecules (hydrated layer), take place. Compared to BC and $\mathrm{KC}, \mathrm{DF}$ is characterized by a greater 2-2.5 times the amount of physically adsorbed water. Thus, the thickness of the hydrated surface layer of fillers increases in a row:

$$
\operatorname{BC}(0.7 \%)<\mathrm{KC}(0.9 \%)<\mathrm{DF}(1.8 \%) \text {. }
$$

At temperatures of $300-900^{\circ} \mathrm{C}$, dehydroxylation processes occur, ie, the loss of chemosorbed water molecules (hydroxyl layer). The surface of DF is characterized by the smallest hydroxyl layer than the surface of the BC and KC. The thickness of the hydroxyl layer of fillers increases in a row:

$$
\mathrm{DF}(1.5 \%)<\mathrm{BC}(9.3 \%)<\mathrm{KC}(13.5 \%) .
$$

Obviously, the established facts substantially affect the acidity of the surface of the fillers. It has previously been established that an increase in the number of physically adsorbed water and the number of hydroxyl groups in the active centers increases the acidity of the surface of inorganic fillers [14]. The results of pK-metric and pH-metric experimental studies of clay fillers are presented in Table 3 and Table 4. 
Table 3. Results of study of clay fillers pK-metric method.

\begin{tabular}{|c|c|c|c|c|}
\hline Filler & $\begin{array}{c}\sum q_{A} \cdot 10^{-12} \\
1 / \mathrm{sm}^{2}\end{array}$ & $\begin{array}{c}\sum q_{B} \cdot 10^{-12}, \\
1 / \mathrm{sm}^{2}\end{array}$ & $\sum q \cdot 10^{-12}, 1 / \mathrm{sm}^{2}$ & $Q$ \\
\hline Bentonite clay (BC) & 108.26 & 119.03 & 227.29 & 0.91 \\
\hline Diabase flour (DF) & 148.55 & 185.23 & 333.78 & 0.80 \\
\hline Kaoline clay (KC) & 78.18 & 120.93 & 199.11 & 0.65 \\
\hline
\end{tabular}

Table 4. Results of study of clay fillers pH-metric method.

\begin{tabular}{|c|c|c|c|c|c|}
\hline Filler & $p H_{0}$ & $p H^{\text {eq }}$ susp & $p H_{I I P}$ & $\Delta p H$ & $\begin{array}{c}\text { Time to set the } \\
\text { equilibrium state, } \mathrm{s}\end{array}$ \\
\hline Bentonite clay (BC) & 7.05 & 7.44 & 7.46 & 0.02 & 300 \\
\hline Diabase flour (DF) & 7.00 & 8.50 & 8.50 & 0 & 360 \\
\hline Kaoline clay (KC) & 7.00 & 9.11 & 9.11 & 0 & 240 \\
\hline
\end{tabular}

From data Table 3 it follows that the acidity of the surface of clay fillers is significantly dependent on the mineral composition. The mineral composition of the $\mathrm{BC}$ and the $\mathrm{KC}$ is almost homogeneous and is represented by the dominant mints montmorillonite and kaolinite, respectively. It is obvious that the presence of these minerals has an almost neutral surface of the $\mathrm{BC}(Q \approx 0,91)$ and a weakly basic $\mathrm{KC}(Q \approx 0,65)$. The composition of DF includes several minerals: leucite, orthoclase, montmorillonite and quartz with impurities of limonite. The nature of the surface DF is intermediate and close to the neutral $(Q \approx 0.80)$. The increase in the alkalinity of the surface $\mathrm{DF}$ compared with the $\mathrm{BC}$ is due to the presence of minerals leucite and orthoclase, which includes potassium oxide $\mathrm{K}_{2} \mathrm{O}$. In addition, alkalinity may provide impurities of limonite, which includes $\mathrm{Fe}_{2} \mathrm{O}_{3}$ ferrous oxide. Thus, according to the results of the pK-metric study, the acidity of the surface of clay fillers increases in a row:

$$
\mathrm{KC}(Q \approx 0,65)<\mathrm{DF}(Q \approx 0,80)<\mathrm{BC}(Q \approx 0,91) .
$$

Concerning the acid-base nature of the surface, the results of the pK-metric study are fully confirmed by the data of the $\mathrm{pH}$-metric analysis. So from the data presented in the Table 4 it follows that the acidity of the surface of clay fillers, in accordance with the value of $\mathrm{pH}_{I I P}$, increases in a row:

$$
\mathrm{KC}(9.11)<\mathrm{DF}(8.50)<\mathrm{BC}(7.46) .
$$

Comparing the obtained series 5 and 6 of 4 and 3 it can be concluded that the mineral composition is the determining factor in the acid-base surface properties of the clay fillers. In this case, the thickness of the hydrated and hydroxyl surface layer to a small extent affects the acidity of the surface. This effect, obviously, becomes significant at certain large sizes of the hydroxyl-hydrated layer. On the surface of the clay fillers studied, the thickness of the surface hydroxyl-hydrated layer is not sufficient to significantly affect the acid-base nature of the surface.

From data Table 3 shows that the largest number of active adsorption centers is characterized by the surface DF $\left(\sum q=333.78 \cdot 10^{12} 1 / \mathrm{sm}^{2}\right)$. This is consistent with the maximum duration of the establishment of the equilibrium state in aqueous suspensions DF (360 s). It should be noted that these indicators are also consistent with the $\mathrm{BC}$ and $\mathrm{KC}$ : the larger the total number of surface active centers, the greater the duration of the time to establish equilibrium state in aqueous suspensions. According to the results of Table 4 the spectrum of active surface centers of clay fillers is not wide. This conclusion follows from the fact that the values of $\Delta p H$ are zero or close to zero. Therefore, most surface active centers of clay fillers have similar values of $p K_{a}$. 


\section{Conclusions}

As a result of the research, the following conclusions can be drawn. The mineral composition, surface morphology, dispersion and specific surface of dispersed clay fillers of various chemical natures have been experimentally determined. Using the thermogravimetric (TG) analysis and the differential thermal analysis (DTA), the structure of the hydroxyl-hydrated surface layer of the fillers surface has been studied. The amount and acidic strength of the surface active centers of clay fillers were investigated using $\mathrm{pK}$ metric and $\mathrm{pH}$-metric methods. It was established that the mineral composition is the determining factor in the acid-base surface properties of clay fillers. In this case, the thickness of the hydroxyl-hydrated surface layer affects the surface acidity to a small extent. It has been shown that clay fillers, which include montmorillonite as the dominant minerals, are characterized by higher acidity than the fillers that consist of kaolinite. In the mixed clay fillers, the acid-base properties of the surface depend on the chemical nature of the impurities and related minerals.

\section{References}

1. E.F. Kudina, Polym. Mater. and Tech., 3, 2, 49-55 (2017)

2. V.A. Andronov, Yu.M. Danchenko, A.V. Skripinets, O.M. Bukhman, Nauk. Visn. Natsion. Hirn. Univ., 6, 85-91 (2014)

3. A.D. Eselev, Polym. Sci. Ser. D, 2, 2, 71-74 (2009)

4. Y-X. Fui, Z-X. He, D-C. Mo, Adhesives Appl. Therm., 66, 493-498 (2014)

5. Yu. Danchenko, V. Andronov, M. Teslenko, V. Permiakov, E. Rybka, R. Meleshchenko, A. Kosse, Eastern-Europ. Journ. of Enterprise Tech., 1, 12 (91), 9-17 (2018)

6. C. Zapata-Massot, N. Le Boley, Part. Part. Charact., 24, 339-344 (2007)

7. Yu. Danchenko, V. Andronov, E. Barabash, T. Obigenko, E. Rybka, R. Meleshchenko, A. Romin, Eastern-Europ. Journ. of Enterprise Tech., 6, 12 (90), 4-12 (2017)

8. P. Cardiano, R.C. Ponterio, S. Sergi, S. Lo Schiavo, P. Piraino, Polymer, 46, 6, $1857-$ 1864 (2005)

9. E. G. Karayannidou, D.S. Achilias, I.D. Sideridou, Europ. Polym. J., 42, 12, 33113323 (2006)

10. Yu. Danchenko, M. Kachomanova, Ye. Barabash, Chem. and Chem. Tech., 12, 2, 188195 (2018)

11. Yu. Danchenko, V. Andronov, A. Kariev, V. Lebedev, E. Rybka, R. Meleshchenko, D. Yavorska, Eastern-Europ. Journ. of Enterprise Tech., 5, 12 (89), 20-26 (2017)

12. C. M. Miller, Submitted to the Office of Graduate Studies of Texas A\&M University in partial fulfillment of the requirement for the degree of Master of Science, 218 (2010)

13. Yu. M. Danchenko, Polym. Mater. and Tech., 3, 2, 56-63 (2017)

14. Yu. Danchenko, V. Andronov, E. Rybka, S. Skliarov, Eastern-Europ. Journ. of Enterprise Tech. 4/12 (88), 17-25 (2017)

15. A. Baldan A., J. of Mater. Sc., 39, 1-49 (2004)

16. K. Weissenbach, H. Mack, Functional fillers for Plastics, 59-83 (2005) 